Research Article

\title{
The Tunnel Structural Mode Frequency Characteristics Identification and Analysis Based on a Modified Stochastic Subspace Identification Method
}

\author{
Biao Zhou $\mathbb{D}^{1,2}{ }^{1,2}$ Xiongyao Xie, ${ }^{1,2}$ and Xiaojian Wang ${ }^{1,2}$ \\ ${ }^{1}$ Key Laboratory of Geotechnical \& Underground Engineering, Ministry of Education, Tongji University, Shanghai 200092, China \\ ${ }^{2}$ Department of Geotechnical Engineering, Tongii University, Shanghai 200092, China \\ Correspondence should be addressed to Biao Zhou; zhoubiao@tongji.edu.cn
}

Received 2 August 2018; Accepted 22 October 2018; Published 2 December 2018

Academic Editor: Filippo Ubertini

Copyright (c) 2018 Biao Zhou et al. This is an open access article distributed under the Creative Commons Attribution License, which permits unrestricted use, distribution, and reproduction in any medium, provided the original work is properly cited.

With the rapid development of underground engineering in China, the heavy structural maintenance work followed is expected to be a great challenge in the future. The development also provides a promising application prospect for the newly developed vibration-based health assessment and monitoring methods. However, the fact that tunnels are embedded in soil makes collecting and identifying the vibration characteristics more difficult, especially for the online monitoring. In this paper, a new identification method that combines the natural excitation technique (NExT) and stochastic subspace identification (SSI) method is developed. The new method is compared with the traditional SSI method, and mode frequency analysis is made based on a series of field tests carried out at the subway and power tunnel. It is found that both stability and efficiency of the mode frequency identification have been greatly improved, and it more suitable for online monitoring. Meanwhile, a mathematical model is used to analyze the original mode characteristics and the influence of soil coupling. The results are also compared with the field tests results by using the NExT-SSI method, and some recommendations are also made for how to choose the vibration modals for vibration-based monitoring in the tunnel.

\section{Introduction}

At present, the underground engineering is gradually moving from the large-scale construction stage into the following heavy maintenance stage in China. The safe operation of underground facilities is threatened by the increasing servicing time and the increasing number of the surrounding construction activities, such as the large excavation. Therefore, the health monitoring system is greatly needed to determine the service state of underground facilities in real time. The static level gauge and crack meter are frequently used to monitor tunnel settlement and joint opening $[1,2]$, which can effectively prevent large deformation and leakage accidents caused by improper construction behavior such as deep excavation around subway tunnels. However, the related static health monitoring method can only characterize the structural behavior near the monitoring points, and the dense layout is thus needed and difficult to obtain the structural elastic modulus and other indicators directly. It can be used instead of some nondestructive testing methods, but the detection efficiencies of these methods are difficult to meet the real-time requirements for large-scale applications. Therefore, there is a strong need of developing health monitoring methods based on vibration or wave propagation characteristics which have sensing capability of the overall underground structure and the surrounding soil.

The present wave or vibration-based methods can utilize characteristics of wave propagation within the structures or the normal vibration modes to identify structural performance. Examples of current structural healthy monitoring (SHM) techniques include using fiber optics, ultrasonics, piezoelectrics and acoustic emissions, thermography, and embedded thin film [4-6]. For these methods, the effective 
identification and extraction of vibration characteristics become very important. For applications in bridges and high-rise buildings, the vibration modes and related methods are more commonly used, e.g., the natural frequency and frequency response function (FRF) spectrumbased methods [7], the mode shape-based methods [8], the model and related matrix-based methods [9], and the data driven methods [10]. Some signal processing techniques have also been proposed for vibration characteristics extraction [11].

It is well known that the soil-structure interaction will change the wave propagation characteristics $[12,13]$, since the underground structures are strongly coupled with the surrounding soil, and the constraining and damping effects and the dynamic behaviors of surrounding soil will cause major challenges for the identification of vibration characteristics [14]. In previous studies, the difference between frequency and dispersion characteristics of the subway tunnel with or without surrounding soil is studied by numerical calculation [15-17]. It is found that the mode frequency is more difficult to identify from the frequency spectrum under the condition of soil coupling. Health monitoring of underground pipelines is mostly based on wave propagation characteristics and related methods [18-20]. Leinov et al. [21], Vogt et al. [22], and Eybpoosh et al. [23] found that the propagation modes and their dispersion characteristics of the propagating ultrasonicguided waves changed from the pipeline to the surrounding medium. Meanwhile, a series of signal processing and modal parameter identification methods have been proposed, such as the peak-picking method, the random decrement technique (RAMA) [24], the natural excitation technique (NExT) [25], and the stochastic subspace identification (SSI) method [26]. The NExT is a method of mode testing that allows structures to be tested in their ambient environments, where the auto- or cross-correlation function is used for mode identification. The SSI method is originally presented by van Overschee and de Moor [27], and an extension of the original SSI method that does not require output covariance was proposed by Peeters and de Roeck $[28,29]$ as the reference-based SSI. The stochastic realization algorithm mainly focused on the data-driven method (SSIDATA) that considers the problem of identifying a stochastic state-space model from output-only data. As opposed to SSI-DATA, the covariance-driven stochastic subspace identification (SSI-COV) algorithm is also developed to avoid the computation of orthogonal projection. Furthermore, to reduce the effect of noise on the results of identification, some filtering techniques need to be used to enhance the early emergence of a stable diagram for the identifiable modes. For instance, SSI is combined with multivariate singular spectrum analysis (MSSA) for vibration monitoring of the rotating turbine system [30]. These methods are widely used in bridges and high-rise buildings, but their applicability in the underground engineering remains to be explored.

An equally important consideration in developing the monitoring system is minimizing the amount of data processing and improving the stability and robust of the monitoring network. Automatic processing technology is also used to reduce the amount of data transmission from the terminal nodes to the server. Therefore, the following key problems need to be considered in the application of the vibration-based monitoring method to tunnels and other underground structures:

(1) Understanding of the tunnel-soil coupling effect on the tunnel dynamic characteristics, and selection of the appropriate vibration characteristics for determining the current structural state

(2) Proper signal processing and vibration characteristics identification methods with high stability and accuracy

(3) Development of the self-processing and automatic identification capability of terminal nodes to meet the low energy cost and robust needs of the wireless network transmission

In this paper, to explore the vibration characteristics of the tunnel and its identification method, a series of field tests are carried out at the subway and power tunnels with different diameters of $6.4 \mathrm{~m}$ and $3.2 \mathrm{~m}$. The SSI-COV method is used, and the NExT is also combined as the filtering techniques to identify tunnel mode natural frequency, and some comparisons on the difference between using SSI-COV and NExT-SSI-COV method on the result of identification are carried out through the stability diagram. At last, a theoretical pipe-in-pipe ( $\mathrm{PiP})$ model [31] is employed to study the distribution of the vibration modes, and some scientific suggestions for the tunnel mode parameters identification are provided at last.

\section{The NExT-SSI-COV Method}

The SSI-COV method is a well-known multivariate identification technique. However, the uncertainty of parameter selection, such as the Toeplitz matrix row number [32] and the long input data will result in the sharp drop of the computational efficiency and stability. In this study, the NExT method is employed and combined with the SSI-COV method to reduce the singularity of covariance matrix and improve the calculation efficiency and stability. The details and process of this method are shown in Figure 1.

\section{Step 1. Form the input matrix $\mathbf{N}$ by the NExT method.}

The autocorrelation function $a_{\mathrm{mm}}$ of every measurement points and cross-correlation function $a_{\mathrm{mn}}$ for any two measurement points were calculated by the NExT method [33], and the formed matrix is denoted as $\mathbf{N} \in \mathbb{R}^{l \times n}$, where $l$ is the number of autocorrelation and crosscorrelation functions and $n$ is the sampling number of the NExT method. The $n$ value is always less than 2048 for identifying the low-frequency modes. Therefore, compared with the conventional SSI-COV method, the size and singularity of the input matrix will be greatly reduced and the computational efficiency and stability can be obviously improved. 
(i) Calculate the correlation function matrix $N$ by NExT method $N=\left[a_{11} \ldots a_{i j}\right] \in \mathrm{R}^{n \times l}, a_{i j}$ is the correlation function of every two measurement points

\section{$\sqrt{2}$}

(ii) Form the output Hankel matrix $Y^{s}$ from matrix $N$ $Y^{s}=\left[\begin{array}{c}Y_{p} \\ \bar{Y}_{f}\end{array}\right] \in \mathrm{R}^{2 n L \times k}, k=l-L+1$ is the user-defined index

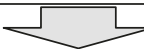

(iii) Calculate the covariance matrix $P\left(P=Y_{p} Y_{f}^{T}\right)$

$$
\checkmark 2
$$

(iv) Calculate SVD of $P$ and determine the order $n$ by neglecting the smaller singular values in $S_{2}$

$$
P=U S V^{T}=\left(\begin{array}{ll}
U_{1} & U_{2}
\end{array}\right)\left(\begin{array}{ll}
S_{1} & 0 \\
0 & S_{2}
\end{array}\right)\left(\begin{array}{c}
V_{1}^{T} \\
V_{2}^{T}
\end{array}\right)
$$

(v) Calculate the extended observability matrix $\Gamma_{L}=U_{1} S_{1}^{1 / 2}$

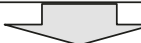

(vi) Calculate the system parameter matrices $A$ and $C$ $A=\underline{\Gamma}_{L}^{\prime} \bar{\Gamma}_{L}, \underline{\Gamma}_{L}$ denotes $\Gamma_{L}$ without the last $l$ rows while $\bar{\Gamma}_{L}$ without the first $l$ rows; $C=$ the first $l$ rows of $\Gamma_{L}$

\section{$\sqrt{2}$}

(vii) Determine the model frequency $\omega_{n}$ and damping coefficient $\xi_{n}$ $\omega_{n}=\frac{a_{n}}{2 \pi \Delta t} ; \omega_{n}=\frac{\left|b_{n}\right|}{\sqrt{a_{n}^{2}+b_{n}^{2}}}$, where $a_{n}=\left|\arctan \left(\frac{\operatorname{Im}\left(\lambda_{n}\right)}{\operatorname{Re}\left(\lambda_{n}\right)}\right)\right|, b_{n}=\ln \left(\lambda_{n}\right) \mid$

FIgure 1: The flowchart of the NExT-SSI-COV method.

Step 2. Form the output Hankel matrix $\mathbf{Y}^{\mathrm{s}}$ from input matrix N.

Firstly, as Equation (1) shows, a series of block matrix $\mathbf{y}_{i}$ are obtained with a time lag $i$ from the input matrix $\mathbf{N}$, and every block matrix $\mathbf{y}_{i}$ has $l$ lines same as $\mathbf{Y}_{\mathbf{N}}$. And the data Hankel data matrix is established by the future measurements matrix $\mathbf{Y}_{\mathrm{f}}$ and past measurements $\mathbf{Y}_{\mathrm{p}}$ as Equation (1) shows:

$$
\mathbf{Y}^{s}=\frac{1}{\sqrt{j}}\left[\begin{array}{cccc}
y_{0} & y_{1} & \cdots & y_{j-1} \\
y_{1} & y_{2} & \cdots & y_{j} \\
\vdots & \vdots & \ddots & \vdots \\
y_{i-1} & y_{i} & \cdots & y_{i+j-2} \\
\hline y_{i} & y_{i+1} & \cdots & y_{i+j-1} \\
y_{i+1} & y_{i+2} & \cdots & y_{i+j} \\
\vdots & \vdots & \ddots & \vdots \\
y_{2 i-1} & y_{2 i} & \cdots & y_{2 i+j-2}
\end{array}\right]=\left(\frac{\mathbf{Y}_{\mathrm{p}}}{\mathbf{Y}_{\mathrm{f}}}\right) \frac{\text { "past" }}{\text { "future" }}
$$

Step 3. Obtain covariance-driven Hankel matrix $\mathbf{P}$ by the conventional matrix and then form the block Toeplitz matrix by a multiplication between future measurements matrix $\mathbf{Y}_{\mathrm{f}}$ and transpose of past measurements $\mathbf{Y}_{\mathrm{p}}$ based on Equation (2):

$$
\begin{aligned}
\mathbf{P} & =\left[\begin{array}{cccc}
R_{i} & R_{i-1} & \cdots & R_{1} \\
R_{i+1} & R_{i} & \cdots & R_{2} \\
\vdots & \vdots & \ddots & \vdots \\
R_{2 i-1} & R_{2 i-2} & \cdots & R_{i}
\end{array}\right] \\
& =\left(\begin{array}{cc}
C \\
C A \\
\cdots \\
C A^{i-1}
\end{array}\right)\left(A^{i-1} G \cdots A^{\prime} G\right)=\mathbf{Y}_{\mathrm{f}}\left(\mathbf{Y}_{\mathrm{p}}\right)^{T}, \\
R_{i} & =E\left[\begin{array}{cc}
y_{k+i} & \left.y_{k}^{T}\right]
\end{array}\right]=\lim _{j \longrightarrow \infty} \frac{1}{j} \sum_{k=0}^{j-1} y_{k+i} y_{k}^{T} .
\end{aligned}
$$

Step 4. Perform singular value decomposition (SVD) on the Hankel covariance matrix $\mathbf{P}$ and obtain eigenmatrix $\mathbf{S}$ $[28,29]$. Then, separate the matrix $\mathbf{S}$ into two submatrices $\mathbf{S}_{1}$ and $S_{2}$ by reducing the eigenvalues. The smallest singular values in the matrix $\mathbf{S}$ are grouped as $\mathbf{S}_{2}$ and will be neglected in the following steps by parameters Csvd. The Csvd can be calculated by the following equations:

$$
\begin{aligned}
\mathbf{P} & =U S V^{T}=\left(\begin{array}{ll}
U_{1} & U_{2}
\end{array}\right)\left(\begin{array}{cc}
S_{1} & 0 \\
0 & S_{2}
\end{array}\right)\left(\begin{array}{c}
V_{1}^{T} \\
V_{2}^{T}
\end{array}\right) \\
& =U_{1} S_{1} V_{1}^{T}, \\
\operatorname{Csvd} & =\frac{\sum V_{S_{\mathrm{n}}}}{\sum V_{S}},
\end{aligned}
$$

where $\sum V_{S_{\mathrm{n}}}$ is the cumulative value of the first $n$ eigenvalues for the $\mathbf{S}$ matrix and $\sum V_{S}$ is the cumulative value of all eigenvalues.

Steps 5 7. Based on the conventional SSI-COV method, the extended observability matrix $\Gamma_{L}$ is firstly calculated according to Equation (5), and then the system parameter matrices $\mathbf{A}$ and $\mathbf{C}$ and mode frequency $\omega_{n}$ and damping coefficient $\xi_{n}$. are obtained separately by Equations (6) and (7) $[34,35]$ :

$$
\begin{aligned}
\Gamma_{L} & =S_{1}^{1 / 2} V_{1}^{T}, \\
A & =\underline{\Gamma}_{L}^{\prime} \bar{\Gamma}_{L}, \\
C & =\text { the first } L \text { rows of } \Gamma_{L},
\end{aligned}
$$

where $\Gamma_{-}$and $\bar{\Gamma}_{L}$ denote $\Gamma_{L}$ without the last $L$ rows and the first $L$ róns, respectively: 


$$
\begin{aligned}
\omega_{n} & =\frac{a_{n}}{2 \pi \Delta t}, \\
\omega_{n} & =\frac{\left|b_{n}\right|}{\sqrt{a_{n}^{2}+b_{n}^{2}}}, \\
\text { where } a_{n} & =\left|\arctan \left(\frac{\operatorname{Im}\left(\lambda_{n}\right)}{\operatorname{Re}\left(\lambda_{n}\right)}\right)\right|, \\
b_{n} & =\ln \left(\lambda_{n}\right) .
\end{aligned}
$$

\section{Field Test and Mode Frequency Identification of a Power Tunnel}

3.1. Measurement Site and Arrangement. As Figure 2 shows, the measured power tunnel is a pipe jacking tunnel, which consists of concrete pipes with a length of $2.5 \mathrm{~m}$. The outer diameter is $3.2 \mathrm{~m}$, and inner diameter is $2.7 \mathrm{~m}$. Nine accelerometers (LANCE 130 series) are installed at the wall and the bottom of the tunnel. Three of them are equipped at each measured point to collect the response from the radical, longitudinal, and tangential directions, and the letter $\mathrm{R}$ means the sensor is installed in the radial direction; $\mathrm{L}$ means the longitudinal direction, while $\mathrm{T}$ is the tangential direction.

3.2. Ambient Vibration Test. To compare the response characteristics of the tunnel in daytime and nighttime, the ambient vibration test is continued for seven days. Acceleration response records of 30 minutes in the nighttime and daytime, respectively, at the measurement point B-1 are shown in Figure 3. For the measured power tunnel close to a subway, the vibration from the operational trains makes the vibration amplitude at daytime about 4 times than that at night. Based on the above data, the tunnel mode frequency characteristics are studied, and a comparison on the difference between using SSI-COV and NExT-SSI-COV on the result of identification is carried out through the construction of a stability diagram. The stability diagram has been proved very helpful to identify the dominant frequencies of the vibration mode while using the SSI-COV method [32].

3.2.1. The Tunnel Response Characteristics at Night. To analyze the tunnel response characteristics at night, with the 30-minute records collected from nine accelerometers, the input matrix dimension will be $3600000 \times 9$ using the traditional SSI method. The stability diagram can be obtained and is shown in Figure 4 after running for three hours on a microcomputer with an Intel i5 processor. While the NExT method is employed, based on the procedures of Step 1 and Step 2 introduced in Section 2, the auto- and crosscorrelation functions of every degree of freedom were calculated with a sampling window of 2048 points and the input matrix $\mathbf{N}$ is formed with the matrix dimension of $2048 \times 28$.
The operation time of the stability diagram on the same microcomputer then can be reduced to less than 2 minutes. The calculation results are shown in Figure 5.

By comparing the stability diagrams of Figures 4 and 5, it was observed that several modes between 10 and $15 \mathrm{~Hz}$ can be found in Figure 4 by using the SSI-COV method directly, but the data fluctuation along the number of rows makes it difficult to identify the natural frequency automatically and accurately. It thus will limit its application of SHM at the underground structure. However, as the NExT method is combined, there is only one mode left with the frequency of $10.5 \mathrm{~Hz}$. In addition, in the implementation of SSI-COV, the selecting Csvd in Step 4 at Section 2 can lead to a change in the number of the vibration modes and their identification accuracy. From Figure 5, it is observed that there is almost no change on the identified model frequencies as the Csvd value changes from 0.815 to 0.915 by using the NExT-SSICOV method. Therefore, the NExT method can develop the mode frequency identification stability and accurately and make it much suitable for application in the underground structure.

\subsubsection{The Tunnel Response Characteristics at Daytime.} The tunnel response characteristics are analyzed during the daytime, especially for considering those vibration modes excited by the train-induced vibration from the nearby subway. By employing the method both of traditional SSICOV method and NExT-SSI-COV method, a 30-minute record is used and the stability diagrams are shown in Figure 6. By comparing Figures 6(a) and 6(b), the mode frequency identification accuracy and stability are improved by using the NExT-SSI-COV method. Meanwhile, it also can be observed that besides $10.5 \mathrm{~Hz}$, there are much more recognition results that can be found from Figure 6, and several modes of which are around $48 \mathrm{~Hz}$ of which is close to the subway track-rail resonant frequency.

From the ambient test at the power tunnel both at daytime and nighttime and by comparing the stability diagrams of using the traditional SSI method and modified method, it is found that the NExT-SSI-COV method has better mode natural frequency recognition accuracy and stability, and several mode frequencies can be clearly identified around $10.5 \mathrm{~Hz}, 48 \mathrm{~Hz}$, and $71 \mathrm{~Hz}$ from the ambient test. Especially for the frequency of 10.5, stability can be recognized both at daytime and nighttime.

3.3. Hammering Test. The mode hammering test is a commonly used method to study the mode characteristics and has a wider test frequency band than the ambient test. Thus, it was also carried out at the power tunnel along the radial, longitudinal, and tangential directions. The impulse load is applied at the connecting steel ring of the tunnel segment (Figure 7(a)), the time history of the pulse load is shown in Figure 7(b), and the frequency test band is around $300 \mathrm{~Hz}$ as shown in Figure 7 (c).

The NExT-SSI-COV method is also used here to analyze the acceleration response, and the stability diagrams are shown in Figure 8. From Figure 8(a), the modes at $53 \mathrm{~Hz}$, 


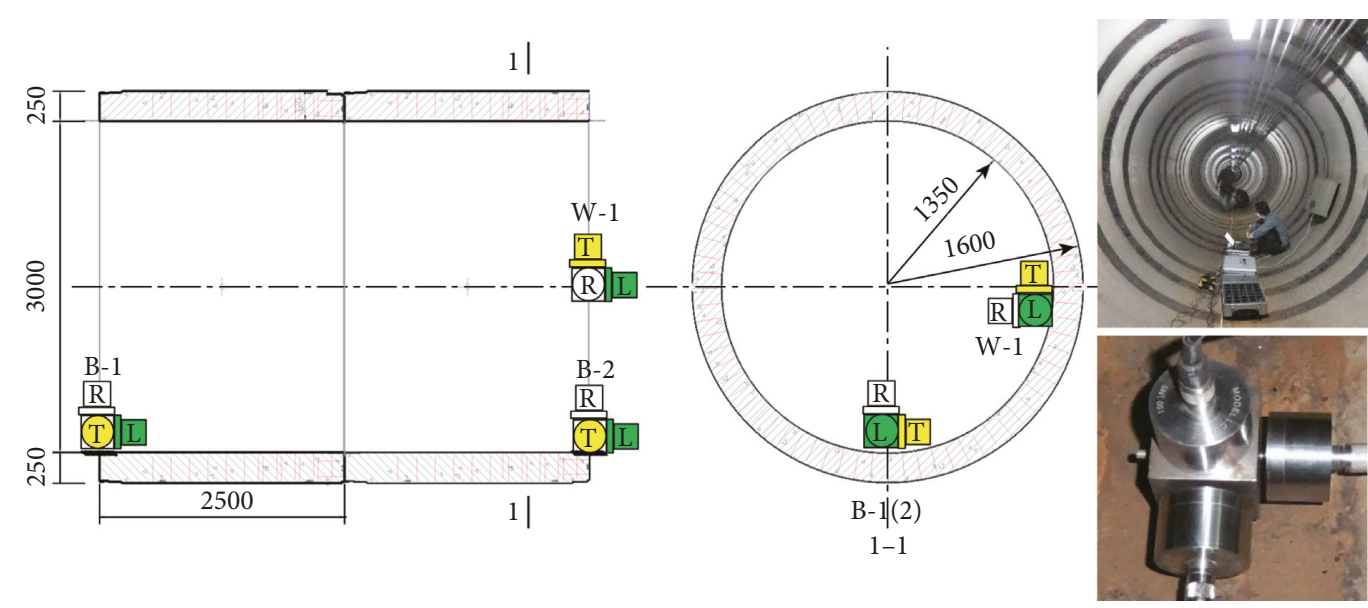

T Tangential
L L Longitudinal
(R) Radial

Figure 2: Arrangement map for the site measurement at the Xizang Road power tunnel.

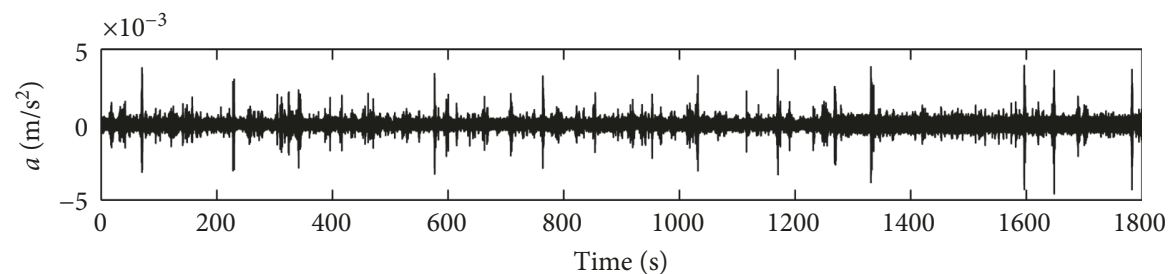

(a)

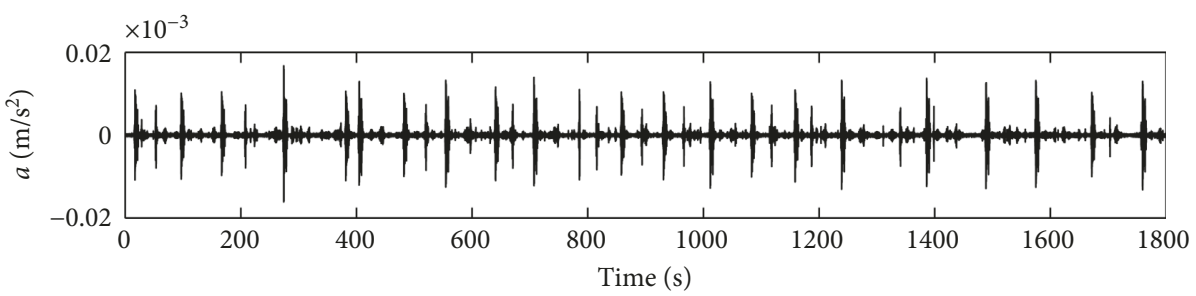

(b)

Figure 3: The time history of the acceleration for the measurement points B-1: (a) at nighttime; (b) at daytime.

$203 \mathrm{~Hz}$, and $223 \mathrm{~Hz}$ can be identified from the radical responses as hammered along the radial direction of the tunnel. And much more modes can be found from the longitudinal direction response as hammered along the longitudinal direction, and there are stable recognition results at $10.5 \mathrm{~Hz}, 15 \mathrm{~Hz}, 108 \mathrm{~Hz}, 123 \mathrm{~Hz}, 203 \mathrm{~Hz}$, and $223 \mathrm{~Hz}$. When the excitation is applied along the tangential direction along the top pipe, from the stability diagram of longitudinal directional response, four modes at $10.5 \mathrm{~Hz}, 123 \mathrm{~Hz}, 203 \mathrm{~Hz}$, and $223 \mathrm{~Hz}$ can be clearly identified.

By comparing with the results of the ambient test, besides the first mode of $10.5 \mathrm{~Hz}$, there are much more modes at $53 \mathrm{~Hz}, 123 \mathrm{~Hz}, 203 \mathrm{~Hz}$, and $223 \mathrm{~Hz}$ that can be found by hammering excitation. Among them, the stability determination of the mode at $53 \mathrm{~Hz}$ means that the modes around $48 \mathrm{~Hz}$ that are found from the ambient test in
Figure 6 are false modes, and it is generated by the train vibration of the nearby subway.

\section{Field Test and Mode Frequency Identification of a Subway Tunnel}

For analysis of the tunnel mode characteristics with different sizes, a mode hammer test is also applied in the nearby subway tunnel. As shown in Figure 9(b), the internal diameter of the tunnel is $5.5 \mathrm{~m}$, and the outer diameter is $6.2 \mathrm{~m}$. The structure of each ring is assembled from six segments, and the thickness of the segment is $35 \mathrm{~cm}$. There is one bidirectional (1-3) and three radial acceleration sensors (1-1, 1-2, and 2-1) placed on the tunnel structure to collect the response from different directions as shown in Figure 9. The hammer pulse's frequency spectrum is shown in Figure 10. 


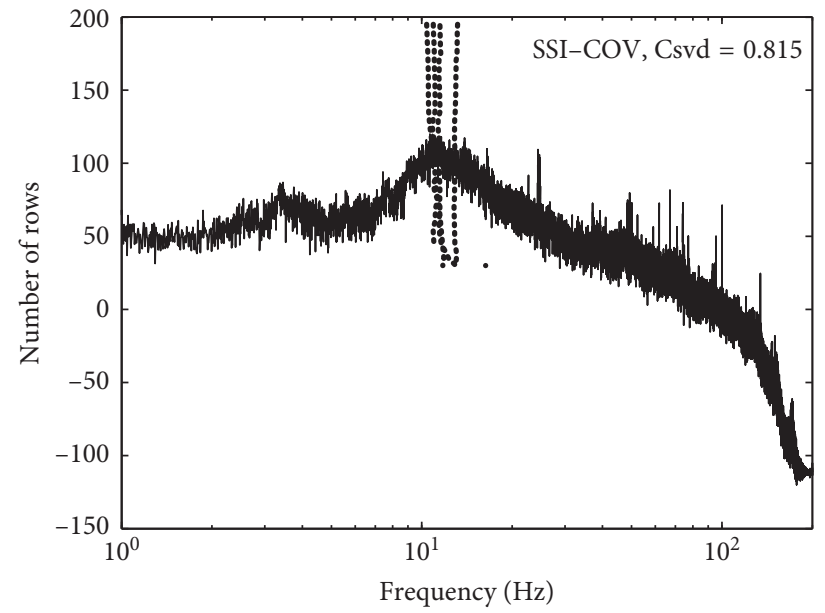

(a)

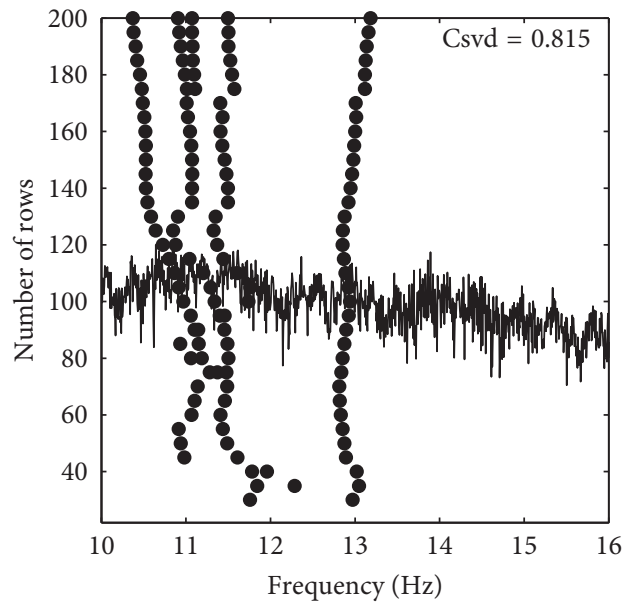

(b)

FIgURE 4: The stability diagram of the data collected at night by using the traditional SSI COV method.

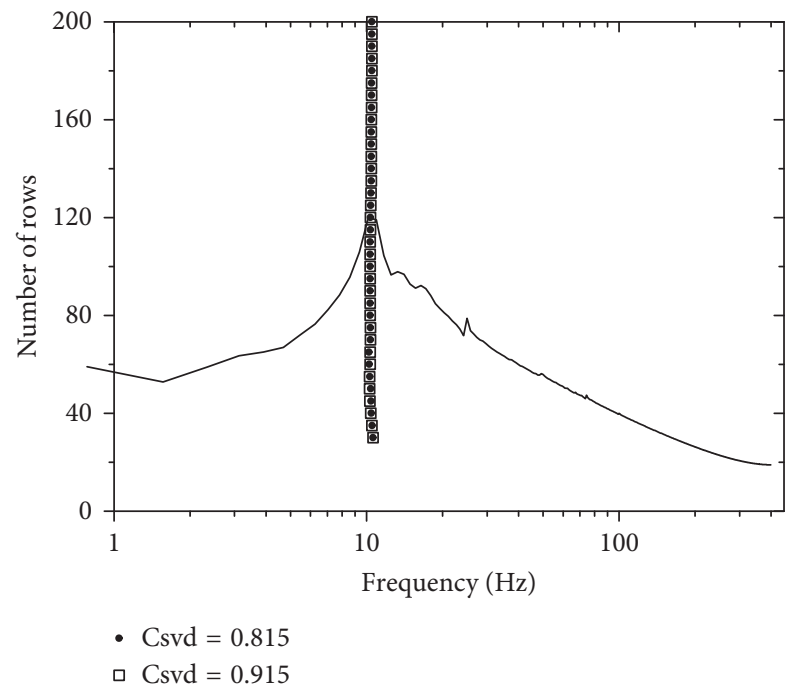

FIgURE 5: The stability diagram of the data collected at night by using the NExT-SSI-COV method.

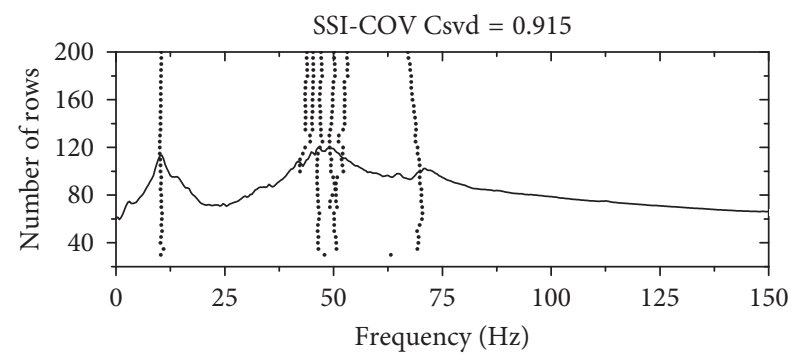

(a)

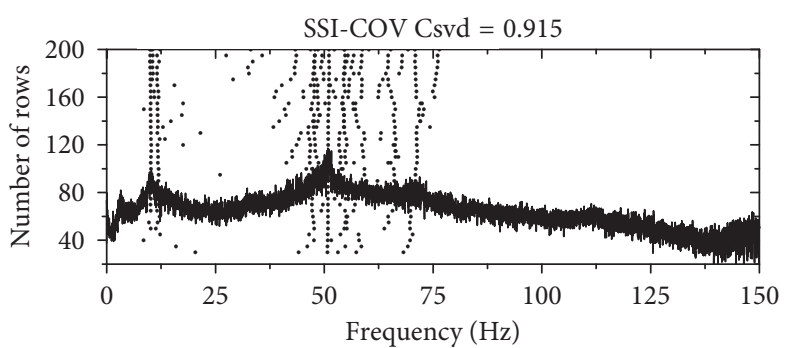

(b)

FIgURE 6: The comparison of the stability diagram of the data collected at daytime: (a) NExT-SSI-COV method; (b) traditional SSI-COV method.

The SSI-NExT method is employed to the acceleration response collected in the tunnel, and the stability diagrams are shown in Figure 11. From Figure 11(a), two modes can be found from the radial response at $142.5 \mathrm{~Hz}$ and $233 \mathrm{~Hz}$. And relatively stable recognition results can be obtained at
$23.5 \mathrm{~Hz}$ and $128.5 \mathrm{~Hz}$ in the longitudinal response (Figure $11(\mathrm{~b})$ ) and $119 \mathrm{~Hz}$ and $128.5 \mathrm{~Hz}$ in the tangential direction (Figure 11(c)). In addition, it is also observed that there are two peaks at $10.75 \mathrm{~Hz}$ and $176 \mathrm{~Hz}$ which appear at the spectrum function from Figure 11 and $10.75 \mathrm{~Hz}$ of 


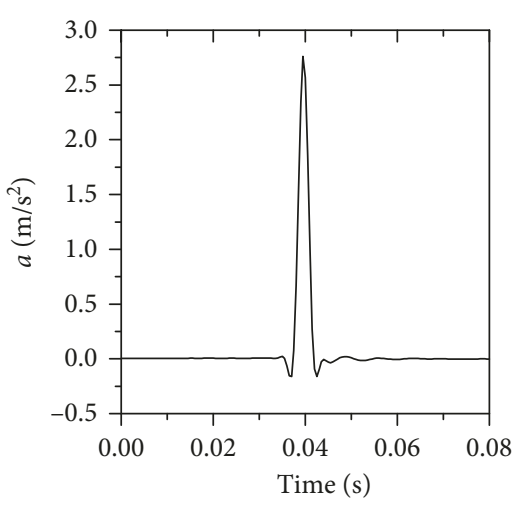

(a)

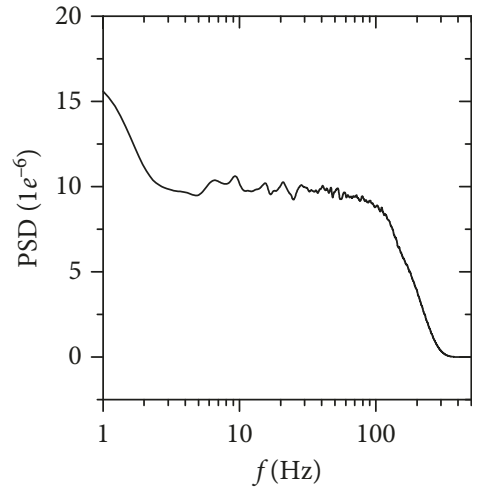

(b)

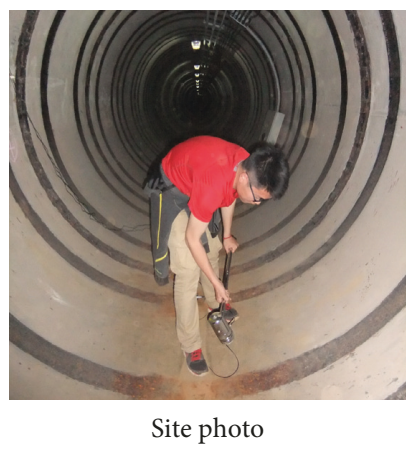

(c)

FIgURE 7: The hammer mode test at the power tunnel.

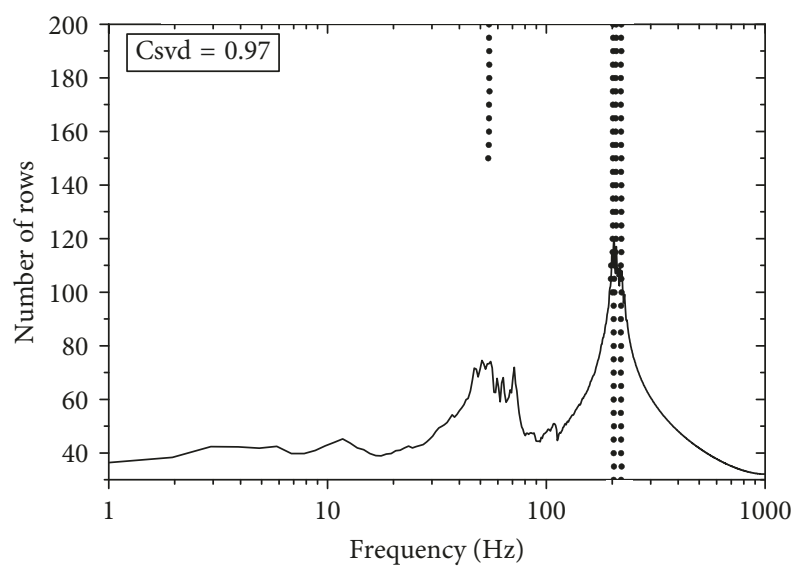

(a)

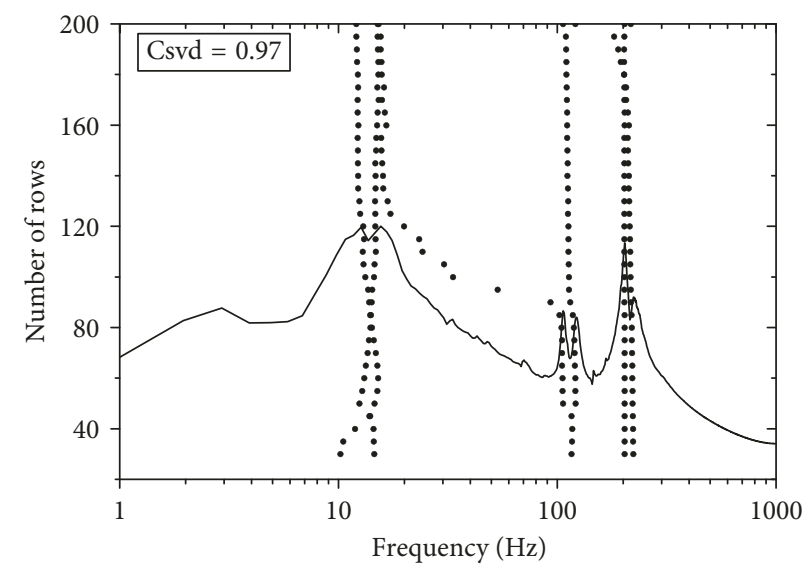

(b)

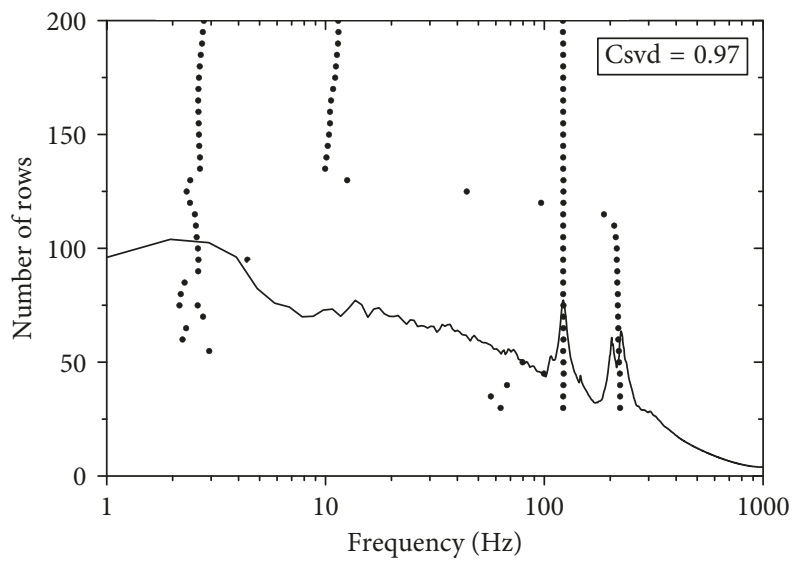

(c)

FIGURE 8: The stability diagrams of the response by applying impulse along different directions at the power tunnel: (a) radical; (b) longitudinal; (c) tangential directions.

which is close to one of the power tunnel's natural frequency at $10.5 \mathrm{~Hz}$.

From the tests and analysis introduced at above, it can be seen that the modes of the tunnel can be stably identified from the hammer test by using the NExT-SSI-COV method.

\section{Numerical Verification and Analysis}

As the SSI method may generate false mode, the dispersion analysis is thus carried out in this section to explore the vibration modes distribution both of the tunnel mentioned above based on the pipe-in-pipe (PiP) model [31]. By 

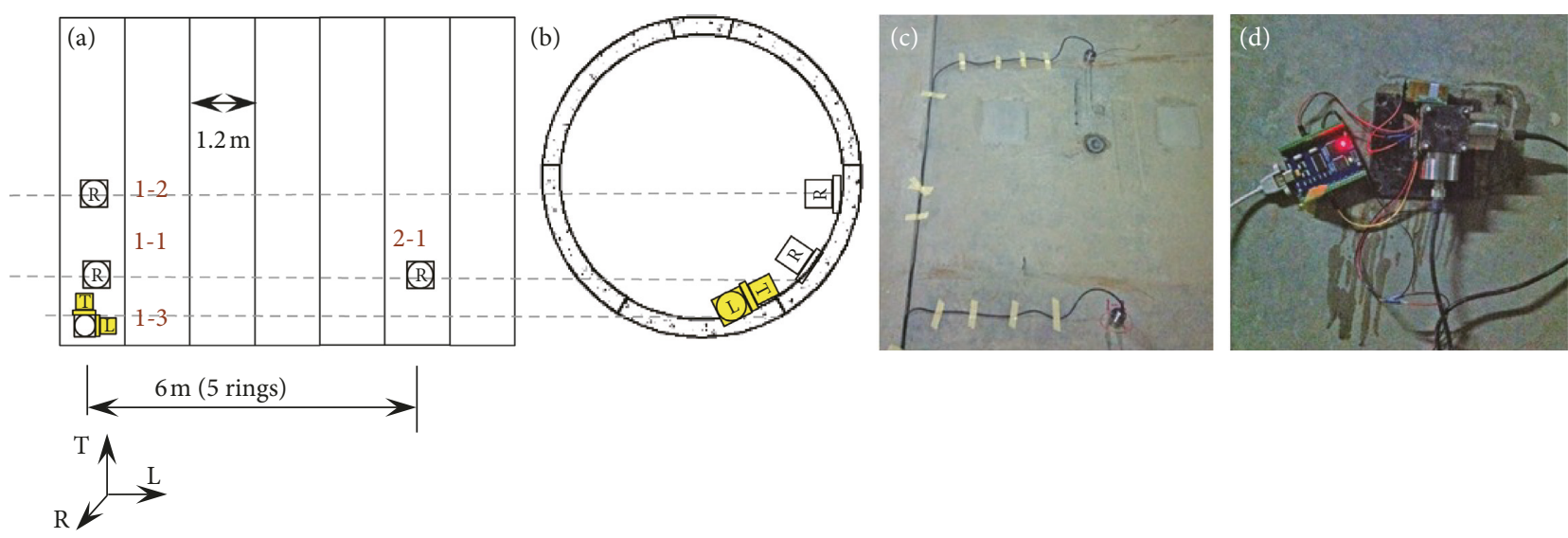

\begin{tabular}{|l|l}
\hline $\mathrm{T}$ & Tangential \\
$\mathrm{L}$ & Longitudinal
\end{tabular}

R. Radial

1-1 Measure point number

Figure 9: Arrangement map for the site measurement at the subway tunnel.

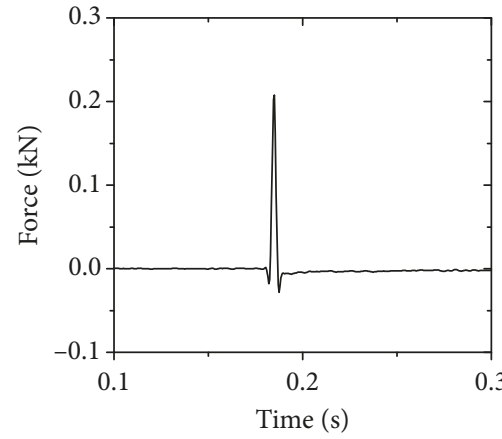

(a)

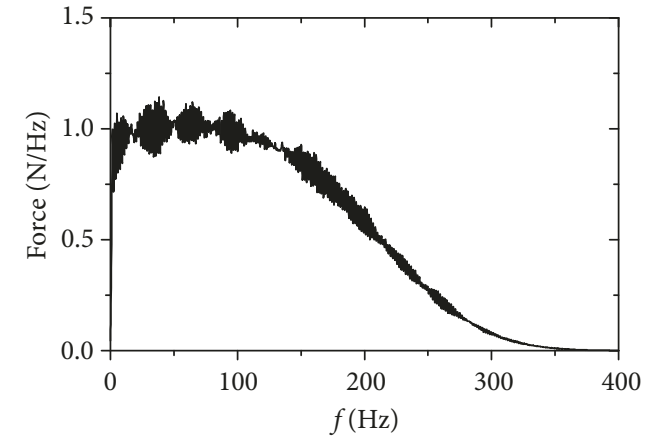

(b)

FIGURE 10: The hammer impulse load applied in the subway tunnel: (a) time spectrum; (b) frequency spectrum.

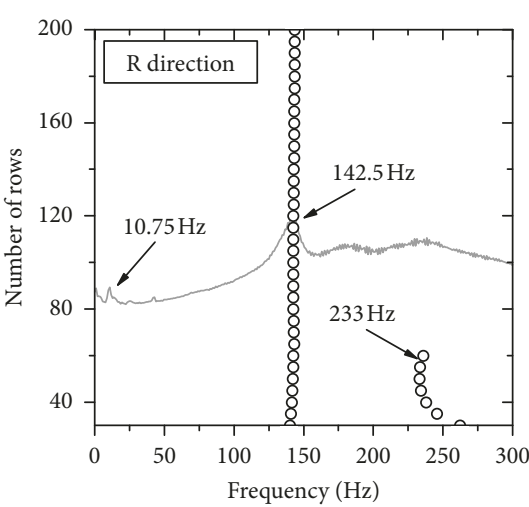

(a)

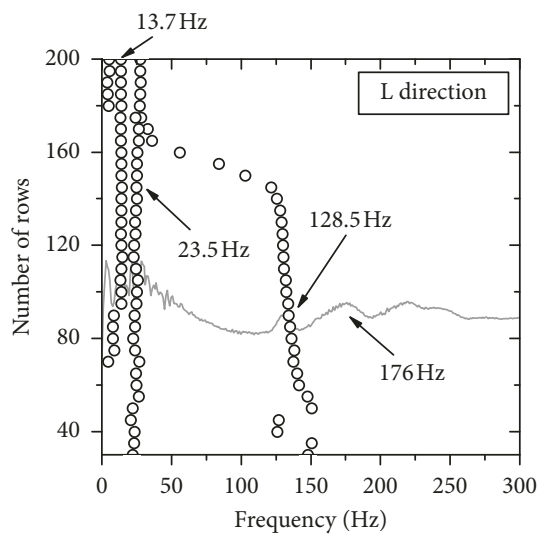

(b)

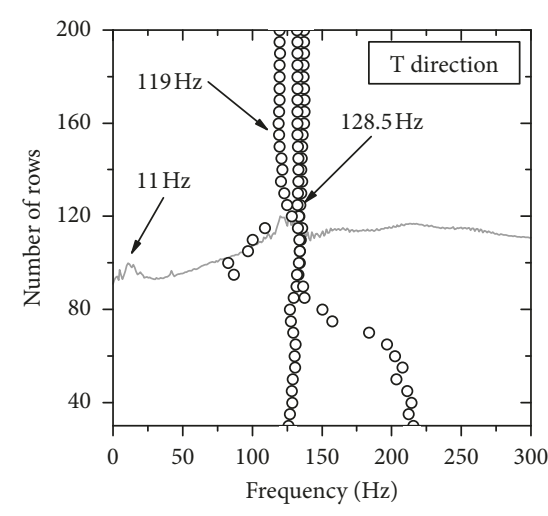

(c)

Figure 11: The stability diagrams of the response by applying impulse along different directions at the subway tunnel: (a) radical; (b) longitudinal; (c) tangential directions. 
comparing the calculated cut-off frequencies with the results from the field test, the structural and soil-body coupling vibration characteristics will be analyzed.

5.1. The PiP Model and Dispersion Analysis. The shield or pipe-jacking tunnel is an assembled structure composed of segments. As Figure 12(a) shows, when only the low frequency response is concerned, it can be approximately analogous to an infinite continuous concrete hollow cylinder due to the wavelength greater than the tunnel segment size. Therefore, the PiP model is introduced here, and the details are given in [17] based on dispersion and wave propagation theories. In this model, as shown in Figure 12(a), the tunnel structure is analogous to an infinite continuous concrete hollow cylinder, and the homogeneous surrounding soil is considered by coupling a concentric 3D thick-walled cylinder outside the tunnel in the PiP model, with its inner diameter set equal to the diameter of the tunnel and outer diameter set to infinity.

The PiP model is established based on the $2.5 \mathrm{D}$ periodic approach [31]. By assuming constant material and geometric properties along the infinite extended direction $x$, and from Figures 12(b) and 12(c), the loads supplied in the tunnel invert can be treated as a sum of sequence of unit harmonic loads along the direction of $x$ and $\theta$. The function can be expressed as shown in Equation (8) in the frequencywavenumber domain:

$$
\widetilde{F}(r, \theta, x, t)=\sum_{n=0}^{\infty}\left[\begin{array}{c}
\widetilde{Q}_{r n} \cos n \theta \\
\widetilde{Q}_{\theta n} \sin n \theta \\
\widetilde{Q}_{x n} \cos n \theta
\end{array}\right] e^{i(k x+\omega t)},
$$

where $\widetilde{Q}_{x n}, \widetilde{Q}_{\theta n}$, and $\widetilde{Q}_{r n}$ are the force components, whose elements are given in [31].

And for a steady response system, it is known that the displacement response can be expressed as the same style with the applied load. Finally, for a given wavenumber $n$, when applying an impulse load at the tunnel invert along different directions, the displacement components of $\widetilde{U}_{n}$, $\widetilde{V}_{n}$, and $\widetilde{W}_{n}$ for the tunnel structure only is shown in Equation (9), and for the tunnel-soil coupled system, the displacement components of $\widetilde{U}_{r n}, \widetilde{U}_{\theta n}$, and $\widetilde{U}_{z n}$ can be calculated by Equation (10) in the frequency-wavenumber domain:

$$
[\mathbf{A}]\left\{\begin{array}{c}
\widetilde{U}_{n} \\
\widetilde{V}_{n} \\
\widetilde{W}_{n}
\end{array}\right\}=\frac{-r\left(1-v^{2}\right)}{E h}\left\{\begin{array}{c}
\widetilde{Q}_{r n} \\
\widetilde{Q}_{\theta n} \\
\widetilde{Q}_{x n}
\end{array}\right\},
$$

where matrix $\mathbf{A}$ is the coefficients matrix, whose elements are given in [31].

$$
\begin{aligned}
& \left\{\begin{array}{l}
\tilde{U}_{r n} \\
\tilde{U}_{\theta n} \\
\tilde{U}_{z n}
\end{array}\right\}_{r=R+(h / 2)}=\mathbf{M}^{\mathrm{T}} \cdot\left\{\begin{array}{l}
\widetilde{Q}_{r n} \\
\widetilde{Q}_{\theta n} \\
\widetilde{Q}_{x n}
\end{array}\right\}_{r=R+(h / 2)}, \\
& \mathbf{M}=\frac{-E h}{a\left(1-v^{2}\right)}[\mathbf{A}]+\left[\begin{array}{lll}
1 & & \\
& -1 & \\
& & -1
\end{array}\right]\left[\mathbf{T}_{\infty}\right]_{r=R+(h / 2)} \\
& \cdot\left[\mathbf{U}_{\infty}\right]_{R+(h / 2)}^{T}\left[\begin{array}{ccc}
-1 & & \\
& & \\
& & \\
& & 1
\end{array}\right],
\end{aligned}
$$

where matrix $\mathbf{T}_{\infty}$ and $\mathbf{U}_{\infty}$ are the $3 \times 3$ complex matrix, whose elements are given in [31].

It is known that the dispersion curves are useful in investigating the mechanism of wave propagation in a medium, which are plotted as the wavenumber $k$ of propagating modes versus the frequency $\omega$. And the mode frequency can be obtained by searching for the cut-on frequency of each propagation mode. There are different methods to calculate the dispersion curves [36]. The most commonly used method is to solve the determinant of the coefficient matrix of the equilibrium equation. As Equation (11) shows, the dispersion relation of the tunnel structure can be obtained by defining the coefficient matrix $\mathbf{A}$ of Equation (9) to zero:

$$
\operatorname{det}(\mathbf{A})=0
$$

where $\mathbf{A}$ is a $3 \times 3$ matrix with the parameters of wavenumber $k$, tunnel density $(\rho)$, Poisson ratio $(\nu)$, segment thickness $(h)$, and tunnel radius which is equal to the average of the inner and outer radii. The detailed description of the matrix $\mathbf{A}$ can be found in [31].

5.2. The Power Tunnel Dispersion Characteristics and Comparison with the Field Test. Based on the PiP model, the dispersion characteristics of the power tunnel will be obtained. According to Equation (4), the parameters are Young's modulus $E_{t}=2.25 \times 10^{4} \mathrm{MPa}$, Poisson's ratio $v=$ 0.2 , density $\rho=2500 \mathrm{~kg} / \mathrm{m}^{3}$, the outer diameter $=3.2 \mathrm{~m}$, and inner diameter $=2.7 \mathrm{~m}$. The tunnel dispersion curves within the range of $0-300 \mathrm{~Hz}$ are obtained and plotted in Figure 13. By dispersion analysis theory, every curve in Figure 13 corresponds to one vibration mode, and the starting frequency at the $x$-axis is the cut-on frequency of the corresponding vibration mode. The vibration modes arise when the excited frequency is higher than the corresponding cuton frequency. The cut-on frequencies of the 2nd-4th propagation modes and the comparison with the field test results are listed in Table 1. 


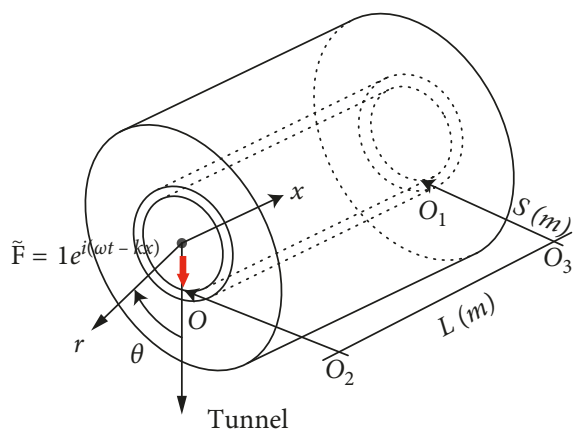

(a)

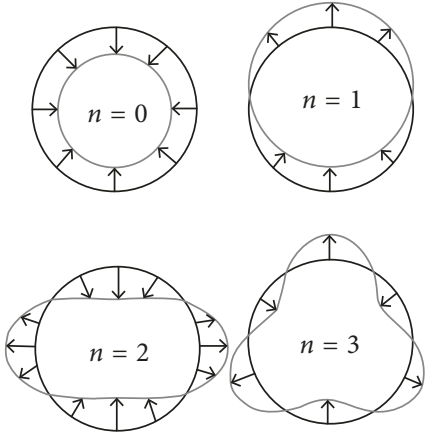

(b)

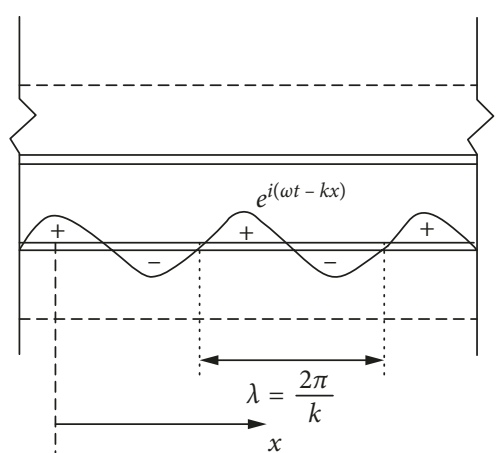

(c)

Figure 12: Decomposition of a radial line load and the resulting tunnel response: (a) the first four Fourier components in cross section; (b) schematic map of the steady response system of the tunnel structure; (c) spatial distribution along the $x$ direction [31].

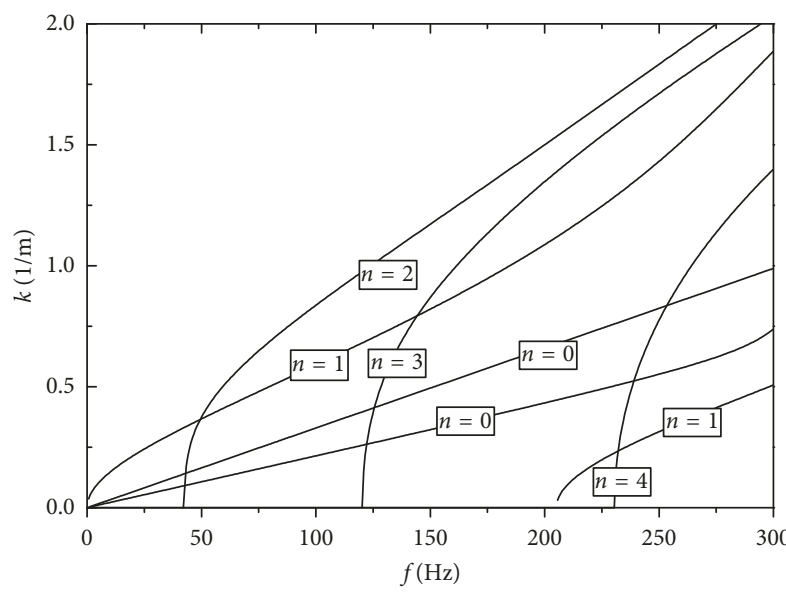

FIGURE 13: Dispersion curves of the power tunnel modeled as a hollow cylinder shell by the PiP model.

TABle 1: The dispersion analysis of the power tunnel mode frequency distribution and comparison with the field test results.

\begin{tabular}{lccccc}
\hline Number & 1 & 2 & 3 & 4 & 5 \\
\hline Dispersion analysis & - & 48 & 121 & 203 & 231 \\
Field test & 10.5 & 53 & 123 & 203 & 223 \\
\hline
\end{tabular}

From Table 1, it is found that most mode frequency plotted in the field test can be found by dispersion analysis. However, $10.5 \mathrm{~Hz}$ has not matched, which can be clearly identified in the ambient vibration test. This may be caused by the coupling effect of the tunnel and surrounding soil, and the discussion will be continued in the following section.

\subsection{The Subway Tunnel Dispersion Characteristics and} Comparison with Field Test. Similarly, the dispersion of the subway tunnel is studied and plotted in Figure 14. Here, Young's modulus $E_{t}=4.35 \times 10^{4} \mathrm{MPa}$, Poisson's ratio $v=$ 0.2 , density $\rho=2500 \mathrm{~kg} / \mathrm{m}^{3}$, the outer diameter $=6.2 \mathrm{~m}$, and inner diameter $=5.5 \mathrm{~m}$. The dispersion curves within the range of $0-250 \mathrm{~Hz}$ are obtained and plotted in Figure 14. And the cut-on frequencies of the propagation modes are compared with the field test results in Table 2.

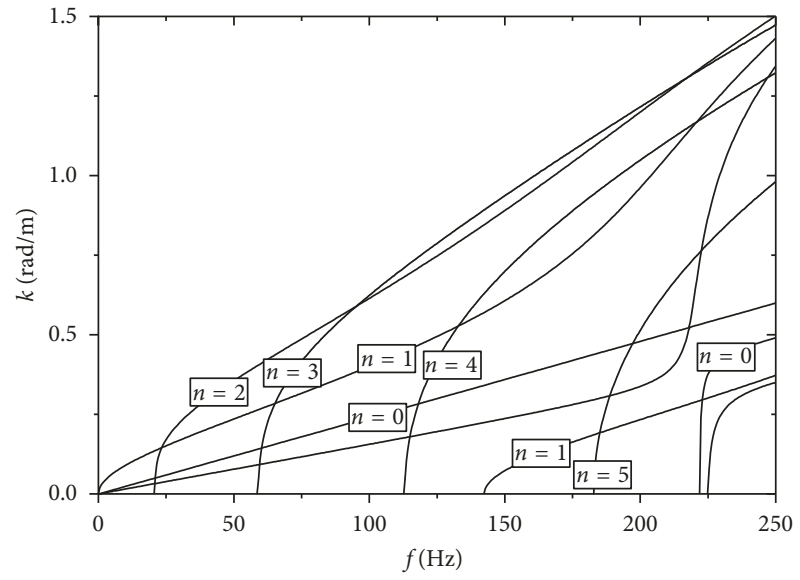

FIGURE 14: Dispersion curves of the subway tunnel modeled as a hollow cylinder shell by the PiP model.

TABLE 2: The dispersion analysis of the subway tunnel mode frequency distribution and comparison with the field test results.

\begin{tabular}{lccccccccc}
\hline Number & 1 & 2 & 3 & 4 & 5 & 6 & 7 & 8 & 9 \\
\hline $\begin{array}{l}\text { Dispersion } \\
\begin{array}{l}\text { analysis } \\
\text { Field test }\end{array}\end{array}$ & - & 21 & 58 & 115 & - & 142 & 183 & 222 & 225 \\
\hline
\end{tabular}

From Table 2, the most cut-on frequencies from dispersion analysis can well match with the field test results. Similarly, the first mode frequency $10.75 \mathrm{~Hz}$ cannot be obtained by dispersion analysis which is close $10.5 \mathrm{~Hz}$ found in the field test of the power tunnel. It is further confirmed that the first mode comes from the surrounding soil or the coupled mode of the tunnel and surrounding soil.

From the analysis above, it can be found that, except the first mode, most of the modes natural frequency identified by the SSI-COV and NExT method are well consistent with the dispersion analysis results. It is proved that the method proposed in this paper has a good accuracy in mode frequency identification. And these modes can be used to track structural changes in tunnels by combing some inversion algorithms. 
And the mismatch of the first mode at $10.5 \mathrm{~Hz}$ of the power tunnel and $10.75 \mathrm{~Hz}$ of the subway tunnel means that it may come from the surrounding soil or generate from the coupling of the tunnel and surrounding soil, and further analysis on the mechanism needs to be discussed in future and is not include here. What is more meaningful is that the first mode can be stability recognized, and it is the only one mode from the ambient test at night, and therefore, it very suitable for monitoring the natural frequency changes caused by soil excavation around the tunnel.

\section{Conclusions}

In this paper, in order to explore the mode frequency distribution of the tunnel and its automatic recognition method, the SSI and NExT methods are combined and applied to analyze the recorded response from ambient and hammer tests and have been proved very suitable for the mode frequency identification in the underground structure. The recognition results are also verified by dispersion analysis based on the PiP model, and some conclusions and suggestion for vibration-based monitoring are obtained as follows:

(1) The first-order mode frequencies can be clearly and stably identified by the ambient test, which has great application potential for monitoring the natural frequency changes caused by soil excavation around the tunnel

(2) Traffic environment excitation in the daytime will interfere with the recognition of structural mode characteristics and result in some false modes

(3) Most of the higher-order vibration modes can be found by the hammer test and are well consistent with the dispersion analysis results. It provides conditions for the analysis of the structural service condition more accurately by some inversion algorithms

\section{Data Availability}

The data used to support the findings of this study are available from the corresponding author upon request.

\section{Conflicts of Interest}

The authors declare that they have no conflicts of interest.

\section{Acknowledgments}

This research was supported by the National Key $R \& D$ Program of China under the grant no. 2018YFC0808702, National Natural Science Foundation of China under the grant nos. 51608379 and 51778476, and Shanghai Science and Technology Innovation Plan Funds under the grant nos. 17DZ1204203 and 18DZ1205200. These supports are greatly appreciated.

\section{References}

[1] H. Zhang, J. Chen, F. Fan, and J. Wang, "Deformation monitoring and performance analysis on the shield tunnel influenced by adjacent deep excavations," Journal of Aerospace Engineering, vol. 30, no. 2, article B4015002, 2015.

[2] J. Y. Han, J. Guo, and Y. S. Jiang, "Monitoring tunnel deformations by means of multi-epoch dispersed 3D LiDAR point clouds: an improved approach," Tunnelling and Underground Space Technology, vol. 38, pp. 385-389, 2013.

[3] T. Hao and C. D. F. Rogers, "Condition assessment of the buried utility service infrastructure," Tunnelling and Underground Space Technology, vol. 28, pp. 331-344, 2012.

[4] X. Y. Xie and L. Feng, "Real-time health monitoring system for power tunnel," in Proceedings of Geo Congress, pp. 3099-3108, Oakland, CA, USA, March 2012.

[5] D. Delaloye, M. S. Diederichs, and G. Walton, "Sensitivity testing of the newly developed elliptical fitting method for the measurement of convergence in tunnels and shafts," Rock Mechanics and Rock Engineering, vol. 48, no. 2, pp. 651-667, 2015.

[6] M. Wilcock, K. Soga, and P. Wright, "Monitoring mechanisms of tunnel lining settlement using instrumented bolts and conventional survey method: assessing neutral axis of longitudinal flexure," Unspecified, pp. 398-407, 2012.

[7] D. Bindi and B. Petrovic, "Seismic response of an 8-story RCbuilding from ambient vibration analysis," Bulletin of Earthquake Engineering, vol. 13, no. 7, pp. 2095-2120, 2015.

[8] D. Daniele and C. Gabriele, "Damage identification techniques via mode curvature analysis: overview and comparison," Mechanical Systems and Signal Processing, vol. 52-53, pp. 181-205, 2016.

[9] F. Musafere, A. Sadhu, and K. Liu, "Towards damage detection using blind source separation integrated with time varying auto-regressive modeling," Smart Materials and Structures, vol. 25, no. 1, article 015013, 2016.

[10] J. A. Goulet, C. Michel, Kiureghian, and A. D. Kiureghian, "Data-driven post-earthquake rapid structural safety assessment," Earthquake Engineering and Structural Dynamics, vol. 44, no. 4, pp. 549-562, 2015.

[11] J. P. Amezquita-Sanchez and H. Adeli, "Signal processing techniques for vibration-based health monitoring of smart structures," Archives of Computational Methods in Engineering, vol. 23, no. 1, pp. 1-15, 2016.

[12] Z. N. Ba and X. Gao, "Soil-structure interaction in transversely isotropic layered media subjected to incident plane $\mathrm{SH}$ waves," Shock and Vibration, vol. 2017, Article ID 2834274, 13 pages, 2017.

[13] A. Anvarsamarin, F. R. Rofooei, and M. Nekooei, "Soilstructure interaction effect on fragility curve of $3 \mathrm{D}$ models of concrete moment-resisting buildings," Shock and Vibration, vol. 2018, Article ID 7270137, 13 pages, 2018.

[14] B. Zhou, F. S. Zhang, and X. Y. Xie, "Vibration characteristics of underground structure and surrounding soil underneath high speed railway based on field vibration tests," Shock and Vibration, vol. 2018, Article ID 3526952, 13 pages, 2018.

[15] S. Gupta, M. F. M. Hussein, G. Degrande, H. E. M. Hunt, and D. Clouteau, "A comparison of two numerical models for the prediction of vibrations from underground railway traffic," Soil Dynamics and Earthquake Engineering, vol. 27, no. 7, pp. 608-624, 2007.

[16] B. Zhou, X. Y. Xie, Y. B. Yang, and J. C. Jiang, “A novel vibration-based structure health monitoring approach for the 
shallow buried tunnel," Computer Modeling in Engineering and Sciences, vol. 86, no. 4, pp. 321-348, 2012.

[17] B. Zhou, X. Y. Xie, and Y. S. Li, "A structural health assessment method for shield tunnels based on torsional wave speed," Science China Technological Sciences, vol. 57, no. 6, pp. 1109-1120, 2014.

[18] A. Galvagni and P. Cawley, "The reflection of guided waves from simple supports in pipes," Journal of Acoustical Society of America, vol. 129, no. 4, pp. 1869-1880, 2011.

[19] A. B. Thien, H. C. Chiamori, J. T. Ching, J. R. Wait, and G. Park, "Model-based SHM: the use of macro-fibre composites for pipeline structural health assessment," Structural Control and Health Monitoring, vol. 15, no. 1, pp. 43-63, 2008.

[20] B. K. RaghuPrasad, N. Lakshmanan, N. Gopalakrishnan, K. Sathishkumar, and R. Sreekala, "Damage identification of beam-like structures with contiguous and distributed damage," Structural Control and Health Monitoring, vol. 20, no. 4, pp. 496-519, 2013.

[21] E. Leinov, M. J. S. Lowe, and P. Cawley, "Investigation of guided wave propagation and attenuation in pipe buried in sand," Journal of Sound and Vibration, vol. 347, no. 7, pp. 96-114, 2015.

[22] T. Vogt, M. Lowe, and P. Cawley, "The scattering of ultrasonic guided waves in partly embedded cylindrical structures," Acoustical Society of America, vol. 113, no. 3, pp. 1259-1272, 2003.

[23] M. Eybpoosh, M. Berges, and H. Y. Noh, "Sparse representation of ultrasonic guided-waves for robust damage detection in pipelines under varying environmental and operational conditions," Structural Control and Health Monitoring, vol. 23, no. 2, pp. 369-391, 2016.

[24] P. Andersen, Identification of civil engineering structures using vector ARMA models, Ph.D. thesis, Department of Building Technology and Structural Engineering, Aalborg University, Aalborg, Denmark, 1997.

[25] G. H. James, T. G. Carne, and J. P. Lauffer, "The natural excitation technique (NExT) for modal parameter extraction from operating structures," International of Analytical and Experimental Modal Analysis, vol. 10, no. 4, pp. 260-277, 1995.

[26] Y. C. Liu, C. H. Loh, and Y. Q. Ni, "Stochastic subspace identification for output-only mode analysis: application to super high-rise tower under abnormal loading condition," Earthquake Engineering Structure Dynamics, vol. 42, no. 4, pp. 477-498, 2013.

[27] P. van Overschee and B. L. R. de Moor, Subspace Identification for Linear Systems: Theory-Implementation-Applications, Kluwer Academic Publishers, Dordrecht, Netherlands, 1996.

[28] I. Goethals, L. Mevel, A. Benveniste, and B. D. Moor, "Recursive output only subspace identification for in-flight flutter monitoring," in Proceedings of 22nd International Mode Analysis Conference, Dearborn, MI, USA, 2004.

[29] B. Peeters and G. de Roeck, "Reference-based stochastic subspace identification for output-only mode analysis," Mechanical Systems and Signal Processing, vol. 13, no. 6, pp. 855-878, 1999.

[30] B. Peeters and G. D. Roeck, "Stochastic system identification for operational mode analysis: a review," Journal of Dynamic Systems, Measurement, and Control, vol. 123, no. 4, pp. 659-667, 2001.

[31] J. A. Forrest and H. E. M. Hunt, "A three-dimensional model for calculation of train-induced ground vibration," Journal of Sound and Vibration, vol. 294, no. 4-5, pp. 678-705, 2006.
[32] Y. Wang, X. C. Hang, D. Jiang, X. L. Han, and Q. G. Fei, "Selection method of Toeplitz matrix row number based on covariance driven stochastic subspace identification," Journal of Vibration and Shock, vol. 34, no. 7, pp. 71-75, 2015.

[33] R. E. Akins, "Cross-spectral measurements in the testing of wind turbines," in Proceedings of 9th ASME Wind Energy Symposium, New Orleans, LA, USA, 1990.

[34] J. H. Weng, C. H. Loh, J. P. Lynch, K. C. Lu, P. Y. Lin, and Y. Wang, "Output-only mode identification of a cable-stayed bridge using wireless monitoring systems," Engineering Structures, vol. 30, no. 7, pp. 1820-1830, 2008.

[35] C. H. Loh, K. J. Loh, Y. S. Yang, W. Y. Hsiung, and Y. T. Huang, "Vibration-based system identification of wind turbine system," Structural Control and Health Monitoring, vol. 24, no. 3, article e187, 2016.

[36] X. Sheng, C. J. C. Jones, and D. J. Thompson, “A theoretical study on the influence of the track on train-induced ground vibration," Journal of Sound and Vibration, vol. 272, no. 3-5, pp. 909-936, 2004. 


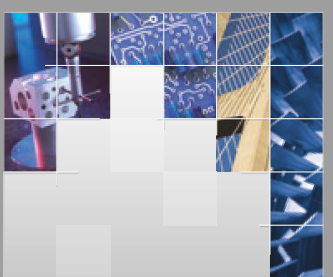

\section{Enfincering}
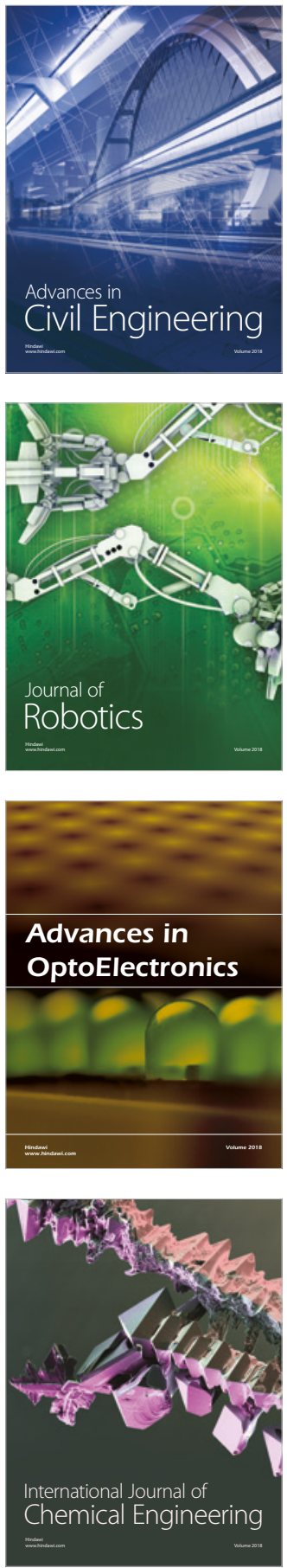

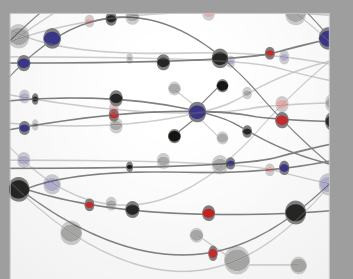

\section{Rotating \\ Machinery}

The Scientific World Journal

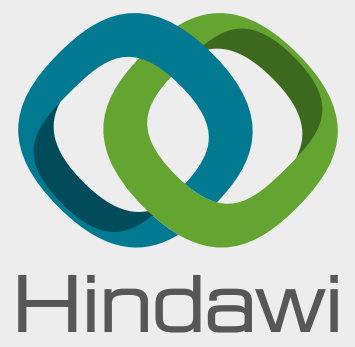

Submit your manuscripts at

www.hindawi.com
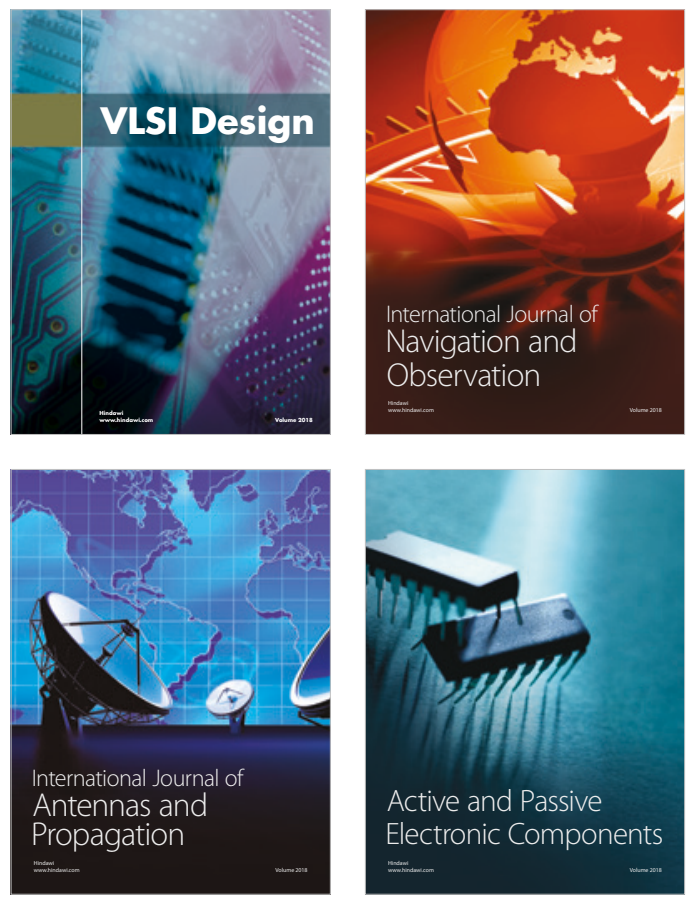
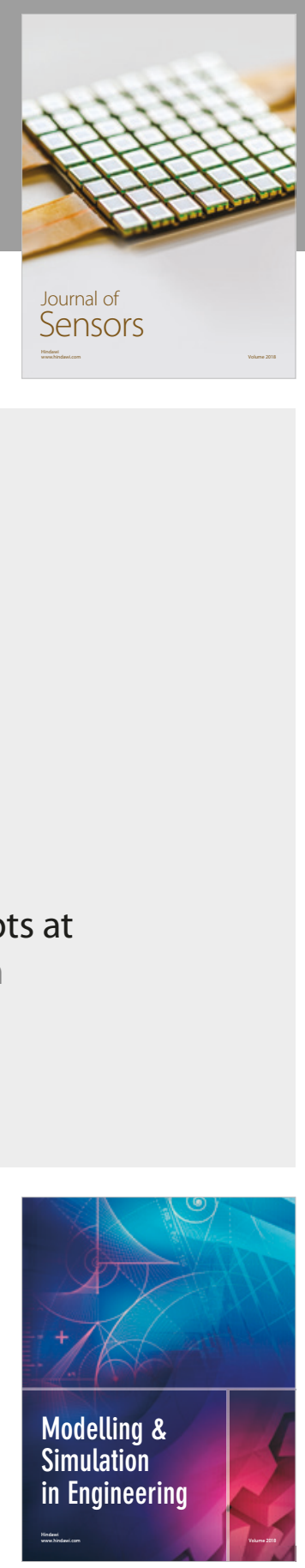

\section{Advances \\ Multimedia}
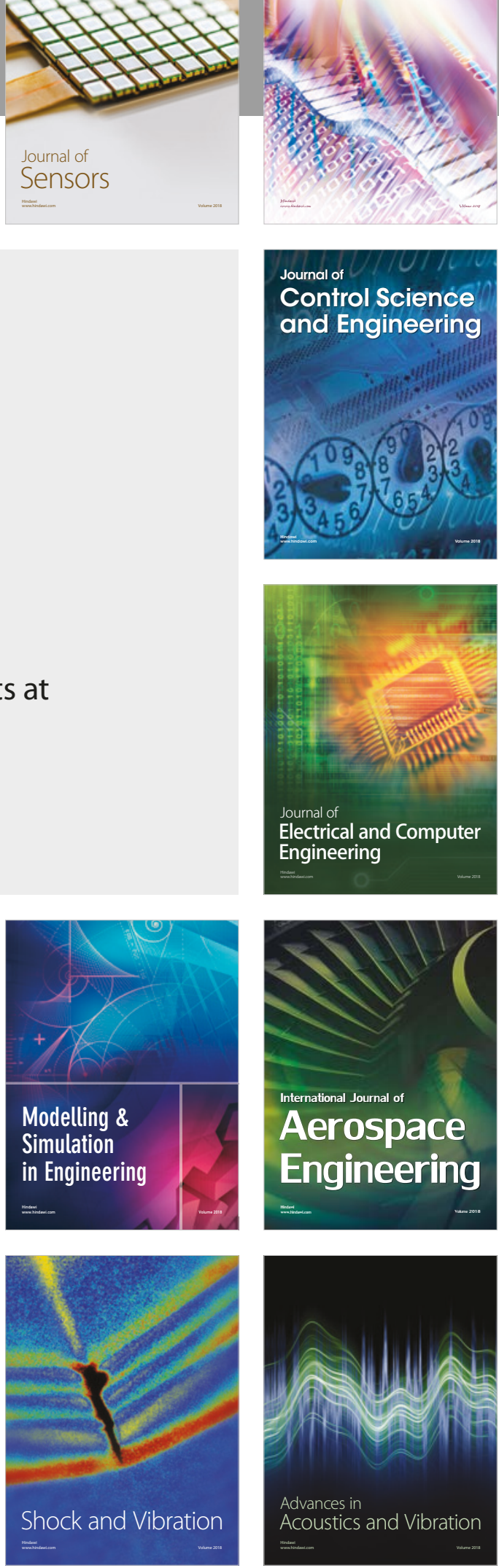